\title{
Correction to: Casein kinase $2 \alpha$ and $\beta$ subunits inversely modulate ABA signal output in Arabidopsis protoplasts
}

\author{
Yukari Nagatoshi ${ }^{1} \cdot$ Miki Fujita $^{2} \cdot$ Yasunari Fujita ${ }^{1,3}$
}

Published online: 17 November 2018

(c) The Author(s) 2018

\section{Correction to: Planta (2018) 248:571-578 https://doi.org/10.1007/s00425-018-2919-5}

The article Casein kinase $2 \alpha$ and $\beta$ subunits inversely modulate ABA signal output in Arabidopsis protoplasts, written by Yukari Nagatoshi, Miki Fujita, and Yasunari Fujita, was originally published electronically on the publisher's internet portal (currently SpringerLink) on 24 May 2018 without open access. With the author(s)' decision to opt for Open Choice the copyright of the article changed on 19 November 2018 to $\odot$ The Author(s) 2018 and the article is forthwith distributed under the terms of the Creative Commons Attribution 4.0 International License (http:// creativecommons.org/licenses/by/4.0/), which permits use, duplication, adaptation, distribution and reproduction in any medium or format, as long as you give appropriate credit to the original author(s) and the source, provide a link to the Creative Commons license and indicate if changes were made.

The original article has been corrected.

Open Access This article is distributed under the terms of the Creative Commons Attribution 4.0 International License (http://creativeco mmons.org/licenses/by/4.0/), which permits unrestricted use, distribution, and reproduction in any medium, provided you give appropriate credit to the original author(s) and the source, provide a link to the Creative Commons license, and indicate if changes were made.

The original article can be found online at https://doi.org/10.1007/ s00425-018-2919-5.

Yasunari Fujita

yasuf@affrc.go.jp

1 Biological Resources and Post-harvest Division, Japan International Research Center for Agricultural Sciences (JIRCAS), Tsukuba, Ibaraki 305-8686, Japan

2 RIKEN Center for Sustainable Resource Science, Tsukuba, Ibaraki 305-0074, Japan

3 Graduate School of Life and Environmental Sciences, University of Tsukuba, Tsukuba, Ibaraki 305-8572, Japan 